\title{
ULTRA-STRUCTURAL STUDIES ON THE MIDGUT OF CULEX PIPIENS LARVAE TREATED WITH POMEGRANATE PEEL EXTRACT, PUNICA GRANATUM
}

\author{
SHAIMAA MAHMOUD FARAG ${ }^{1^{*}}$, MOHAMED ADEL HUSSEIN ${ }^{1}$, SORIYA \\ ELTANTAWY HAFEZ ${ }^{1}$, AMANY SOLIMAN KHALED ${ }^{1}$, OMNIA MOHAMED \\ HELMY MOHAMED KAMEL ${ }^{2}$ AND OLA HELMY ZYAAN ${ }^{1}$
}

Departments of Entomology ${ }^{1}$, Faculty of Science, Ain Shams University, Cairo 11566 and Applied Chemistry ${ }^{2}$, National Research Center, Giza, Egypt

(Correspondence:spodopteralittoralis88@gmail.com)

\section{Abstract}

The peel powder of Punica granatum, extracted with petroleum ether, was proved to have potential toxicological effects against third instar larvae of Culex pipiens. The median lethal dose $\left(\mathrm{LC}_{50}\right)$ value was found to be $95.6632 \mathrm{ppm}$. Qualitative phytochemical screening of pomegranate peel extract was assessed by standard methods. The phytochemical constituents present in petroleum ether extract of Punica granatum peel were phenols and Saponins. The mid gut of the treated larvae was investigated histopathologically and ultra-structurally. The tested extract induced a severe damage to the larval midgut epithelial cells; showing swollen, lysed and displayed clear destruction in the peritrophic membrane and brush border. Also, several changes in cell organelles including destruction of the cell membrane, microvilli, mitochondria, nuclei and cytolysis of gut epithelial cells was observed.

Key words: Culex pipiens, Punica granatum, larvicidal, Pomegranate peel, Midgut epithelium, Histopathology

\section{Introduction}

Mosquitoes are vector of many blood-borne pathogens as malaria, filariasis, Dengue fever, Yellow fever, Zika fever, West Nile fever, Rift Valley fever and others (El-Bahnasawy et al, 2013). Vector control is a very integral part of the current global strategy for the control of mosquito borne diseases (WHO, 2010). Although it was highly efficient against the target species, insecticide applications are facing numerous threats due to the development of resistance strains. Other undesirable effects include hazardous effects against non-target animals, environmental problems and human health concerns (Liu et al, 2006).

Many authors focused their attention on the development of the biodegradable phytopesticides (Massoud and Labib, 2000; Pavela, 2008; Pirali-Kheirabadi and Da Silva, 2010; Bouta et al, 2011; Reegan et al, 2014; Shaalan and Canyon, 2015). Numerous secondary metabolites from plant sources were used as effective bio-pesticides (Mohamed and Hafez, 2000; Mohamed et al,2003; Samuel et al, 2014; Raveen et al, 2015;
Kuppusamy et al, 2016). Ecofriendly active ingredients of plant origin lessen the long term environmental impacts of pesticide use. Furthermore, pests rarely develop resistance against active ingredients of plant origin (Maurya et al, 2012).

In mosquito control programs, so many types of herbs and plant extracts were found to demonstrate larvicidal activity against a wide range of mosquito species (Ansari et al, 2000; Abba et al, 2006; Warikoo and Kumar, 2014; Brione and Garbo, 2016; Subashini et al, 2017). Such larval intoxication and growth regulation of immature and adult mosquitoes were found correlated with histopathological changes in the tested species particularly in the gut that led to certain functional and physiological interactions (AlMekhlafi, 2017).

The present study aimed to evaluate insecticidal activities of (Punica granatum) pomegranate peel crude powder, extracted with petroleum ether, against Culex pipiens $3^{\text {rd }}$ larvae, as well as larval susceptibility to the extract and its cytotoxicity and histopathology on the midgut. 


\section{Materials and Methods}

Preparation of Punica granatum petroleum ether extract: Pomegranate peels were washed in order to be cleaned and then lift to dry under shade in the laboratory. Dried peels were cut into small pieces and ground in an electric grinder. Hundred grams of the resulting powdered materials of peels were exhaustively extracted with petroleum ether. Samples were soaked in respective solvent at 1:5 (w/v) for 72 hours at room temperature $\left(28^{\circ} \mathrm{C}-34^{\circ} \mathrm{C}\right)$ with occasional shaking and, then, filtered using Whatman filter paper. The rest was re-extracted for at least 2 times independently. All filtrates were collected and evaporated at $50^{\circ} \mathrm{C}$ by rotary evaporator (Buchi, Lausanne, Switzerland) to remove solvent content. Then, they were subjected to freeze, drying before storage at $-4 C^{\circ}$ in screw capped vials, until needed.

Phytochemical screening of pomegranate peel extracts were assessed (Savithramma $e t$ al, 2011; Selvaraj et al, 2014).

Colony maintenance: A laboratory susceptible strain of Culex pipiens, used throughout the present investigation, was obtained from the Research and Training Center on vectors of Diseases (RTC), Ain Shams University. The colony was kept in a walk-in chamber insectary at $\left(27 \pm 2^{\circ} \mathrm{C}\right.$ and $70 \pm 10 \%$ relative humidity and a photoperiod of (12 hours light \& 12 hours dark). Mosquito larvae were reared in white enamel dishes containing $1500 \mathrm{ml}$ of distilled water. Newly hatched larvae were fed on fish food (TetraMin, Germany) as a diet. Adult were reared in $(24 \times 24 \times 24 \mathrm{~cm})$ wooden cages and daily provided with $10 \%$ sucrose solution as well as a pigeon for female blood feeding.

Larvicidal bioassay: The larvicidal activity of pomegranate peel extract was evaluated against the third instar larvae of $C x$. pipiens under laboratory conditions $\left(27 \pm 2^{\circ} \mathrm{C}, \mathrm{RH}\right.$ $70 \pm 10 \%$, and 12-12 light-dark regime). Bioassay test was performed according to the standard World Health Organization larval bioassay test method (WHO, 2005).
Batches of 25 third instar larvae of $C x$. pipiens were transferred by a plastic dropper to five small disposable test cups, containing different concentrations of such extract that was diluted with ethanol and ranged from 50 ppm to 500ppm. Control test was carried out with ethanol. Four replicates were performed for each concentration including control test. Mortality was recorded after 24 hours of treatment.

Histopathological studies: The effects of sub-lethal doses of pomegranate peel extract on midgut epithelial cells of $C x$. pipiens, untreated and treated larvae were prepared for ultrastructural studies (Bowen and Ryder, 1976). Larvae were fixed in 3\% glutaraldehyde in $0.1 \mathrm{M}$ cacodylate buffer (PH 7.2) for an hour followed by an overnight wash in fresh patch of the same buffer. Specimens were shortly washed in acetate buffer and incubated for as hour at $37^{\circ} \mathrm{C}$ in medium of 5 tablets of P-nitrophenyl phosphate disodium salt, $25 \mathrm{mg}$ lead acetate and $25 \mathrm{ml}$ acetate buffer. Incubation step was stopped by further washing in cacodylate buffer before post fixing in osmium tetroxide followed by routine dehydration and embedding in araldite. The sections were cut on a ReichertJung Ultra-microtome. Semi and ultrathin sections of $0.5-1.0 \mu \& 20-60 \mathrm{~mm}$ were cut. Semi-thin sections were stained for 1-2 minutes in toluidine blue stain, washed in tape running water, dried and mounted in DPX. The ultrathin sections were stained with uranyl acetate and lead citrate stains and then examined microscopically and photographed with Jeol 1000 TEM, at the Electron Microscope Unit Center, Al-Azhar University, Cairo, Egypt

Statistical analysis: Data were analyzed by statistics package (LDP-line) for good-ness of fit (Chi square test) and to detect $\mathrm{LC}_{50} \&$ $\mathrm{LC}_{90}$ values with corresponding $95 \%$ confidence limits (C.L.), slope, correlation coefficient and standard error.

\section{Results}

The results were shown in tables $(1 \& 2)$ and figures (1 to 17). 
Table 1: Phytochemical screening of pomegranate peel petroleum ether extract

\begin{tabular}{|c|c|}
\hline Chemical constituent & Presence/Absence \\
\hline Tannins & - \\
\hline Saponins & + \\
\hline Flavonoid & - \\
\hline Alkaloids & - \\
\hline Phenols & - \\
\hline Resin & - \\
\hline Sterols & - \\
\hline Quinines & . \\
\hline
\end{tabular}

Table 2: Toxicity of petroleum ether extract of pomegranate peels against $3^{\text {rd }}$ instar larvae of laboratory Cx. pipiens strain

\begin{tabular}{|c|c|}
\hline Concentrations $(\mathrm{ppm})$ & Mortality\% (Mean \pm SE) \\
\hline 50 & $21.33 \pm 0.65$ \\
\hline 100 & $53.33 \pm 0.29$ \\
\hline 200 & $78.66 \pm 0.50$ \\
\hline 300 & $94.66 \pm 0.50$ \\
\hline 500 & $96 \pm 0.00$ \\
\hline Slope & $2.724 \pm 0.2217$ \\
\hline Chi-Square $\left(\chi^{2}\right)$ & 2.8281 (tabulated 6 7.8) \\
\hline Correlation Coefficient $(\mathrm{r})$ & $0.9871($ tabulated 0.878$)$ \\
\hline LC $_{50}($ Its limits at $95 \%)$ & $95.6632(83.5932-107.7178)$ \\
\hline LC $_{90}($ Its limits at $95 \%)$ & $282.6335(242.877-342.445)$ \\
\hline
\end{tabular}

\section{Discussion}

In the present study, the phytochemical constituents of petroleum ether extract of Punica granatum peel showed the presence of saponins and phenols alone, and extraction process yielded $0.611 \%$ crude product.

In the present study, as to insecticidal activity of pomegranate peel extract against $3^{\text {rd }}$ instar larvae of $C x$. pipiens, petroleum ether pomegranate peel extract showed a remarkable toxicity. There was a pattern of concentration-dependent mortality was observed. The used extract induced mortality which increased with increasing concentrations to reach $96 \%$ at $500 \mathrm{ppm}$. The $\mathrm{LC}_{50}$ value was 95.6632ppm. The latter results showed toxicity to larvae by pomegranate peel extract that might be due to the presence of phenol and saponins.

The aforementioned insecticidal activity results agreed with many other authors (Mohammed and Hafez, 2000; Massoud and Labib, 2000; Pelah et al, 2002; Vahitha et al, 2002; Jeyabalan et al, 2003; Prabakar and Jebanesan, 2004; El-Hela et al, 2013). Koide et al. (1998) evaluated the toxicity caused by $P$. granatum in Tribolum confusum due to the stringent properties of tannins con- tained in the peel fruit which stop infestation. Redwane et al. (2002) investigated the toxicity of Quercus lusitania var. and Infectoria galls olive extracts against $2^{\text {nd }}$ instar larvae of $C x$. pipiens. Mohammed et al. (2003) found that extracts of Cymbopogon citratus and Ocimum menthaefolium proved promising control agents against mosquito larvae. Sharma et al. (2006) and Nathan et al. (2006) used methanol extracts of leaves from the chinaberry tree, Melia azedarach L. (Meliaceae) against immature mosquito vector, A. stephensi and recorded that larval mortality was $82 \%$ in first instar. Maurya et al. (2009) evaluated extracts from leaves of $O$. basilicum with several solvents, against A. stephensi and C. quinquefasciatus found that petroleum ether extract was the most effective against the larvae of both mosquitoes. Also, The efficacy of extracts from rhizomes of Curcuma aromatic were tested against the larvae of filariasis vector mosquitos, Cx quinquefasciatus using standard WHO, the soxhlet extraction was carried out using non- polar organic solvent, petroleum ether, proved effective (Madu et al, 2010).

The present ultrastructural studies showed that the mid gut responsible for digestion 
and absorption of the nutrients, with cytoplasm rich with mitochondria and lysosomes. They also have large surface area of microvilli. The well-developed peritrophic membrane was detected along the fore and mid-gut (Figs. 1, 3). In untreated mosquito larvae, the midgut cells were uniformly arranged in one layer and lined with the peritrophic membrane, a well-developed brush border and normal adhesive basement membrane (Figs.1, 3). The anterior mid-gut epithelial cells rest on basal lamina (Figs. $1 \& 3$ ). Nucleus of the columnar cell is basely located (Figs.1, 3). Nucleoplasm (karyolymph) is light in appearance and the chromatin of nucleus is concentrated in one part of the cell (Figs. 1, 3, 4, 5, 7, 8). Mitochondria are scattered throughout the cytoplasm (Figs.4, 5, 6, $7,8,9)$, they are mainly concentrated at the apical parts of the cells, very close to brush borders (Figs. 1, 4, 6, 7, 9). Conspicuous brush border was as a regular array of long, thin large numbers of microvilli (Figs.4, 6, 7, 9). Peritrophic membrane is associated with luminal surface of mid-gut (Figs.1, 3).

In the present study, larvae treated with sub-lethal dose $\left(\mathrm{LC}_{50}=95.6632 \mathrm{ppm}\right)$ showed a histopathological deformity within the gut tissues. After 24 hours, treated larvae suffered severe pathological changes in the structure of the gut wall. In a few number of cells, apical part of the columnar cells appeared empty. Vacuoles were in the cytoplasm of cells and swollen nuclei. Cells were dislodged, sloughed and detached from each other (Figs. 10, 11, 12, 14). Degeneration of peritrophic membrane occurred (Figs. 2). Epithelium of midgut treated with sub lethal concentration of petroleum ether pomegranate peel extract was detached from the basal lamina. Nucleus shape was altered with destruction of chromatin material (Figs. $10,11,12,13,15)$. There were large vacuoles in cytoplasm, severe damage of mitochondria and disorganization of cristae (Figs. 15, 16, 17) and, leakage of the lysosomal enzymes (Fig. 11). Lysis of epithelial cells was observed (Figs.10, 11). Most of microvilli of epithelial cells were destructed (Figs. 2, 12, 13, 16) with gaps or fissures at cell bases (Figs. 10, 11, 13). Gut apical portion of columnar cells was swollen and sometimes distinct elongations protrude into its lumen as a bulbous aversion (Figs. 10\&11). The present results agreed with those reports on insect response to toxic substances (Shoukry, 1996; Massoud and Labib, 2000), they proved a histopathological effect of lethal concentration of oil and oleo resin extracts of Myrrh as larvicidal biocide on mosquito larvae.

In the present study, petroleum ether extract induced lesions within cells. Such injury to cells is due to the effect of tannic acid, typical lesions as described by (Hussein 2001). Also, swelling and separation of apical cells from one another at the intracellular junction complex were developed and dramatically affects the epithelial permeability.

Phytochemical screening showed that only saponins and phenolic compounds are present in petroleum ether extract of pomegranate peels. Saponins are natural glycosides which have a wide range of pharmacological properties including cytotoxic activity. Cytotoxic effect of most saponins was due to their ability to stimulate apoptotic process in living cells, usually by intrinsic pathway. The general cytotoxicity of saponins is dependent on their plasma membrane toxicity and that the membrane toxicity might be caused by the loss of cholesterol molecules from the cell membrane. Podolak et al. (2010) suggested alteration patterns seen in midgut epithelium of treated larvae.

Phenolic compounds are secondary metabolites that are synthesized by plants via the pentose phosphate, shikimate and phenylpropanoid pathways (Randhir et al, 2004). Phenols, after penetration of the cell, underwent active transformation, mainly at participation of oxidases within cytochrome $\mathrm{P}_{450}$. Sometimes transformation processes led to rapid increase of toxicity by forming electrophilic metabolites that damage DNA and/or enzymes in the cell. Cytotoxic effects 
of phenolic compounds depend on reactivity. Phenols exert higher reactivity rapidly undergo radical reactions and provoke lipid peroxidation of a cell's membrane (AbdelHady et al, 2014). The forms of lower activity penetrate cell internal spaces and damage membranes of endoplasmic reticulum, mitochondria and nucleus and biochemical components as enzymes and nucleic acids (Michałowicz and Duda, 2006). There were patterns of deformations (Figs. 15, 16).

\section{Conclusion}

The outcome data proved that petroleum ether extract of pomegranate peels is a promising ecological friend mosquito larvicide. The histopathology showed cytotoxic effects of the extracted.

\section{References}

Abba, U, Larit, KS, Asadabe, OJ, 2006: Susceptibility of Aedes aegypti pupae to neem seed kernel extracts. Anim. Res. Inter. 3, 1:403-6.

Al-Mekhlafi, FA, 2017: Larvicidal, ovicidal activities and histopathological alterations induced by Carum copticum (Apiaceae) extract against Culex pipiens (Diptera: Culicidae). Saudi J. Biol. Sci.http://dx.doi.org/10.1016/j.sjbs.02. 010

Ansari, MA, Razdan, RK, Mamta, T, Padma, V, Tandom, M, et al, 2000: Larvicidal and repellent actions of Dalbergia sisso Roxb.(F: Leguminosae) oil against mosquitoes. Bio-resource Tech., 73, 3:207-11.

Bouta, MB, Silva, GD, Lima, HG, Oliveira, J VA, Souza, TS, et al 2011: In vivo anthelmintic activity of an aqueous extract from sisal waste (Agave sisalana Perr.) against gastrointestinal nematodes in goats. Vet. Parasitol. 177:104-10.

Bowen, ID, Ryder, TA, 1976: Use of the Pnitro phenyl phosphate method for the demonstration of acid phosphatase during starvation and cell autolysis in the planarian, Polycelis tenuis. Hist. Chem. J. 8:319-29.

Briones, AV, Garbo, AG, 2016: Bioactivity of the aqueous and ethanolic extracts/pellet form of Philippine Piper nigrum L. on the duration of egg, larval and pupal development stages of $A e$ des aegypti mosquitoes. J. Entomol. Zool. Stud. 4, 6:196-202.

Clement, AN, 1992: The Biology of Mosquito: Development, nutrition and reproduction Vol.1 Chapman and Hall, London.
Abdel-Hady, NM, El-Hela, AA, Morsy, TA, 2014: Phenolic content of some selected Lamiaceous Egyptian medicinal plants: Antioxidant potential and ecological friend mosquito-larvicidal. J. Egypt. Soc. Parasitol. 44, 1:21-4.

El-Bahnasawy, MM, Abdel Fadil, EE, Morsy, TA, 2013: Mosquito vectors of infectious diseases: Are they neglected health disaster in Egypt? J. Egypt. Soc. Parasitol. 43, 2:373-86.

El-Hela, AA, Abdel-Hady, NM, Dawoud, GT, Hamed, AM, Morsy, TA, 2013: Phenolic content, antioxidant potential and Aedes aegyptii ecological friend larvicidal activity of some selected Egyptian Plants. J. Egypt. Soc. Parasitol. 43, 1:215-34

Hussein, MA, 2001: Histopathological effects of tannic acid on midgut epithelium of mosquito larvae of Culex pipiens. Egypt. Acad. Soc. Environ. Develop. (A-Ent.); 1, 2:107-22.

Jeyabalan, D, Arul, N, Thangamathi, P, 2003: Studies on effects of Pelargonium citrosa leaf extracts on malarial vector, A. stephensi Liston. Bioresour. Technol. 89, 2:185-9.

Koide, T, Nose, M, Inoue, M, Ogiharey, Y, Ya bu, Y, et al, 1998: Trypanocidal effect of gallic acid and related compounds. Planta Medica. 64: 27-30.

Kuppusamy, E, Dhamodharan, KI, Jayakumar, S, 2016: Role of plants and plant based products towards control of insect pests and vectors: A novel review. J. Coastal Life Med. 4, 11: 902-17.

Liu, N, Xu, Q, Zhu, F, Zhang, L, 2006: Pyrethroid resistance in mosquitoes. Insect Sci. 13: 159-66.

Madhu, SK, Shaukath, AK, Vijayan, VA, 2010: Efficacy of bioactive compounds from Curcuma aromatic against mosquito larvae. Acta Trop. 113:7-11.

Massoud, AM, Labib, IM, 2000: Larvicidal activity of Commiphora molmol against Culex pipiens and Aedes caspius larvae. J. Egypt. Soc. Parasitol. 30, 1:101-15.

Maurya, P, Sharma, P, Mohan, L, Batabyal, L, Srivastava, CN, 2009: Evaluation of the toxicity of different phyto-extracts of Ocimum basilicum against Anopheles stephensi \& Culex quinquefasciatus. J. Asia-Pac. Entomol. 12:113-5.

Maurya, P, Sharma, P, Mohan, L, Verma, M M, Srivastava, CN, 2012: Larvicidal efficacy of Ocimum basilicum extracts and its synergistic effect with neonicotinoid in the management of Anopheles stephensi. Asian Pac. J. Trop Dis. 12: 
110-6

Michałowicz, J, Duda, W, 2006: Phenols-sources and toxicity. Polish J. Environ. Stud. 16, 3: 347-62.

Mohammed, MI, Hafez, SE, 2000: Biological and biochemical effects of the non-volatile plant oil (Jojoba) against Culex pipiens (Diptera: $\mathrm{Cu}-$ licidae). J. Egypt. Ger. Soc. Zool.13, A:65-78.

Mohammed, MI, Hammad, REM, Abdel-Fattah, HM, 2003: Larvicidal activity and biochemical effects of certain plant oil extracts against Culex pipiens larvae (Diptera: Culicidae). J. Egypt. Acad. Soc. Environ. Develop. (AEnt.); 3, 1:134-9.

Nathan, SS, Kalaivani, K, Chung, PG, 2006: The effects of azadirachtin and nucleopolyhydrosis virus on midgut enzymatic profile of Spodoptera litura Fab. (Lepidoptera: Noctuidae), Pestic. Biochem. Physiol.83:46-57.

Pavela, R, 2008: Larvicidal effects of various Euro-Asiatic plants against Culex quinquefasciatus Say larvae (Diptera: Culicidae). Parasitol. Res. 102:555-9.

Pelah, D, Abramovich, Z, Markus, A, Wiesman, $\mathbf{Z}, 2002$ : Use of commercial saponin from Quillaje saponaria bark as a natural larvicidal agent against Ae. aegypti and $C x$. pipiens. J. Ethnopharmacol. 81, 3:407-9.

Pirali-Kheirabadi, K, Da Silva, JAT, 2010: Lavandula angustifolia essential oil as a novel \& promising natural candidate for tick (Rhipicephalus (Boophilus) annulatus) control. Exp. Parasitol.http://dx.doi.org/10.1016/j.exppara.04. 012.

Podolak, I, Galanty, A, Soboleweska, D, 2010: Saponins as cytotoxic agents: a review. Phytochem. Rev. 9:425-74.

Prabakar, K, Jebanesan, A, 2004: Larvicidal efficacy of some Cucurbitacious plant leaf extracts against $C$. quinquefasciatus (Say). Bioresour. Technol. 95, 1:113-4.

Randhir, R, Lin, YT, Shetty, K, 2004: Phenolics, their antioxidant and antimicrobial activity in dark germinated fenugreek sprouts in response to peptide and phytochemical elicitors. Asia Pac. J. Clin. Nutr. 13:295-307.

Raveen, R, Samuel, T, Arivoli, S, Madhanagopal, R, 2015: Evaluation of mosquito larvicidal activity of Jasminum species (Oleaceae) crude extracts against the filarial vector Culex quinquefasciatus Say (Diptera: Culicidae). Amer. J. Essent. Oils Nat. Prod. 2, 4:24-8.

Redwane, A, Lazrek, HB, Bouallam, S, Markouk, M, Amarouch, H. et al, 2002: Larvicidal activity of extracts from Quercus Lusitania var. infectoria galls (oliv.). J. Ethnopharmacol. 79, 2: 261-3.

Reegan, AD, Gandhi, MR, Paulraj, MG, Balakrishna, K, Ignacimuthu, S, 2014: Effect of niloticin, a protolimonoid isolated from Limonia acidissima L. (Rutaceae) on the immature stages of dengue vector Aedes aegypti L. (Diptera: $\mathrm{Cu}-$ licidae). Acta Tropica.139:67-76.

Samuel, L, Muthukumaran, RB, Gurusubramanian, G, Senthilkumar, N, 2014: Larvicidal activity of Ipomoea cairica (L.) sweet and Ageratina adenophora (Spreng) King \& H. Rob. Plant extracts against arboviral and filarial vector, Culex quinquefasciatus Say (Diptera: Culicidae). Exp. Parasitol. 141:112-21.

Savithramma, N, Linga, R, Bhumi, G, 2011: Phytochemical screening of Thespesia populnea [L.] Soland and Tridax procumbens L. J. Chem. Pharm. Res. 3, 5:28-34.

Selvaraj, S, Chittibabu, CV, Janarthanam, B, 2014: Studies on phytochemical screening, antioxidant activity and extraction of active compound (Swertiamarin) from leaf extract of Enicostem malittorale. Asian J. Pharm. Clin. Res. 7, 4:240-4.

Sharma, P, Mohan, L, Srivastava, CN, 2006: Phyto-extract-induced developmental deformities in malaria vector. Bio. Resource Technol. 97: 1599-604.

Shaalan EAS, Canyon VD, 2015: A review on mosquitocidal activity of botanical seed derivatives. Curr. Bioact. Comp. 11:78-90.

Shoukry, IFI, 1996: Morphogeneic and histopathological effects induced by two natural volatile oils on the house fly, Musca domestica (L.) (Diptera: Muscidae). Proc. $1^{\text {st }}$ Conf. Role of Science in development; Egyptian Society and Environment, Zagazig University, Egypt.

Subashini, K, Sivakami, R, Jeyasankar, A, 2017: Phytochemical screening and ovicidal ac-t ivity of Scutellaria violacea (Lamiaceae) leaf extract against vector mosquitoes (Diptera: Culicidae). Inter. J. Adv. Res. Biol. Sci. 4, 3:152-8.

Vahitha, R, Venkatachalam, MR, Murugan, K, Jebanesan, A, 2002: Larvicidal efficacy of Pavonia zeylanica L. and Acacia ferruginea D.C. against $C$. quinquefasciatus Say. Bioresour. Technol. 82, 2:203-4.

Warikoo, R, Kumar, S, 2014: Impact of the Argemone mexicana stem extracts on the reproductive fitness and behavior of adult dengue vector, Aedes aegypti L. (Diptera: Culicidae). 
Inter. J. Insect Sci. 6:71-8.

WHO, 2005: Guidelines for laboratory \& field testing of mosquito larvicides. Bull. WHO, 1-41.
WHO, 2010: World Malaria report. Geneva, Switzerland.

\section{Legend of figures}

Fig. 1: T.S of midgut epithelium of untreated larvae, Cx. pipiens: Basement membrane (Bm) adherent to epithelial cells, Spherical nucleus (N), Brush border or microvilli (Mv), Peritrophic membrane $(\mathrm{Pm})$ and gut lumen $(\mathrm{Lu})(\mathrm{x}=400)$

Fig.2: Transverse section of midgut epithelium, $C x$. pipiens larvae treated with $\mathrm{LC}_{50}$ of petroleum ether extract showed destruction of epithelial cells, Peritrophic membrane (Pm) and disappearance of microvilli $(\mathrm{Mv}) .(\mathrm{x}=400)$

Fig. 3: E. M. of midgut cells of untreated mosquito larvae showed epithelial cells with normal nucleus(N), Nuclear envelope (NE), Chromatin $(\mathrm{Ch})$ and mitochondria $(\mathrm{M})(\mathrm{x}=6000)$

Fig. 4: E. M. of midgut of untreated larvae showed normal nucleus (N), nuclear envelope (NE), Nucleolus (Nu), mitochondria (M) and microvilli (MV) $(\mathrm{X}=6000)$

Fig. 5: E. M. of midgut cells of untreated larvae showed normal nucleus (N), normal nucleolus (Nu), brush border or microvilli (MV) and Mitochondria (M) $(\mathrm{x}=6000)$

Fig. 6: E. M. of midgut of untreated larvae showed large number of regular microvilli (MV) and mitochondria ( $\mathrm{x}=8000$ )

Fig. 7: Magnification electron micrograph of midgut cells of untreated larvae showed large number of regular microvilli (MV) and mitochondria scattered through cytoplasm $(\mathrm{X}=15000)$

Fig. 8: E. M. of midgut of untreated larvae showed normal nucleus $(\mathrm{N})$, nucleolus $(\mathrm{Nu})$ and nuclear envelope $(\mathrm{NE})(\mathrm{X}=20000)$

Fig. 9: E. M. of midgut epithelium of untreated larvae showed normal Basement membrane (Bm) adherent to t epithelial cells, Spherical nucleus $(\mathrm{N})$, Peritrophic membrane, circular muscles and longitudinal muscles $(\mathrm{Pm})(\mathrm{x}=6000)$.

Fig. 10: E. M. of midgut of larvae treated with petroleum ether pomegranate peel extract showed abnormal mitochondria with empty contents $(\mathrm{X}=30000)$

Fig. 11: E. M. of midgut of larvae treated with petroleum ether pomegranate peel extract showed disturbance of chromatin material (CH) in nucleus $(\mathrm{N})$ and large number of cytoplasmic vacuoles $(\mathrm{V})(\mathrm{X}=6000)$

Fig. 12: E. M. of midgut of larvae treated with petroleum ether pomegranate peel extract showed disturbance of nuclear envelope (NE), chromatin material $(\mathrm{CH})$ in nucleus $(\mathrm{N})$, malformation of mitochondria, degeneration of microvilli and large number of cytoplasmic vacuoles (V) $(\mathrm{X}=8000)$

Fig. 13: E. M. of midgut of larvae treated with petroleum extract showed degeneration of microvilli and large number of cytoplasmic vacuoles (V) $(\mathrm{X}=20000)$

Fig. 14: E. M. of midgut of larvae treated with petroleum ether extract showed disturbance of chromatin material (Ch) in nucleus (N) degeneration of nuclear envelope (NE), severe damage of mitochondria and cristae disorganization (M) $(\mathrm{X}=25000)$

Fig. 15: E. M. of midgut of larvae treated with petroleum ether extract showed cellular vacuolation(V), disturbance of chromatin material $(\mathrm{CH})$ in nucleus $(\mathrm{N})$ and degeneration of nuclear envelope $(\mathrm{Ne})(\mathrm{X}=15000)$

Fig. 16: E. M. of midgut of larvae treated with petroleum ether extract showed cellular vacuolation , disturbance of chromatin material $(\mathrm{CH})$ in nucleus $(\mathrm{N})$ and degeneration of nuclear envelope $(\mathrm{NE})$, obvious septum between epithelial cells and degeneration of microvilli of epithelial cells $(X=8000)$

Fig. 17: E. M. of midgut of larvae treated with petroleum ether extract showed degeneration of muscle layers, mitochondria(M), microvilli of epithelial cells, cellular vacuolation, disturbance of chromatin material $(\mathrm{CH})$ in nucleus $(\mathrm{N})$, obvious septum between epithelial cells and degeneration of nuclear envelope $(\mathrm{Ne})(\mathrm{X}=4000)$.
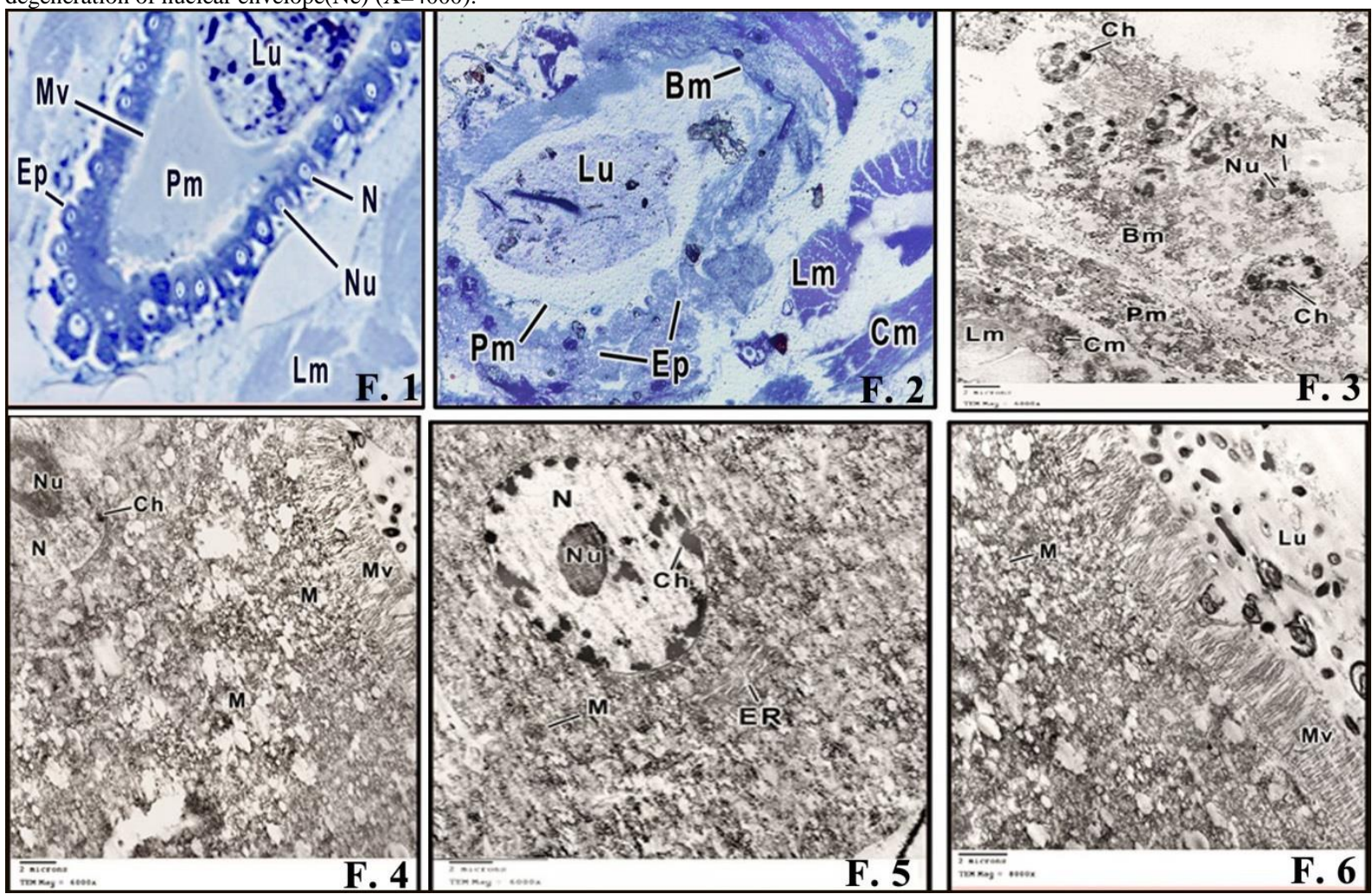

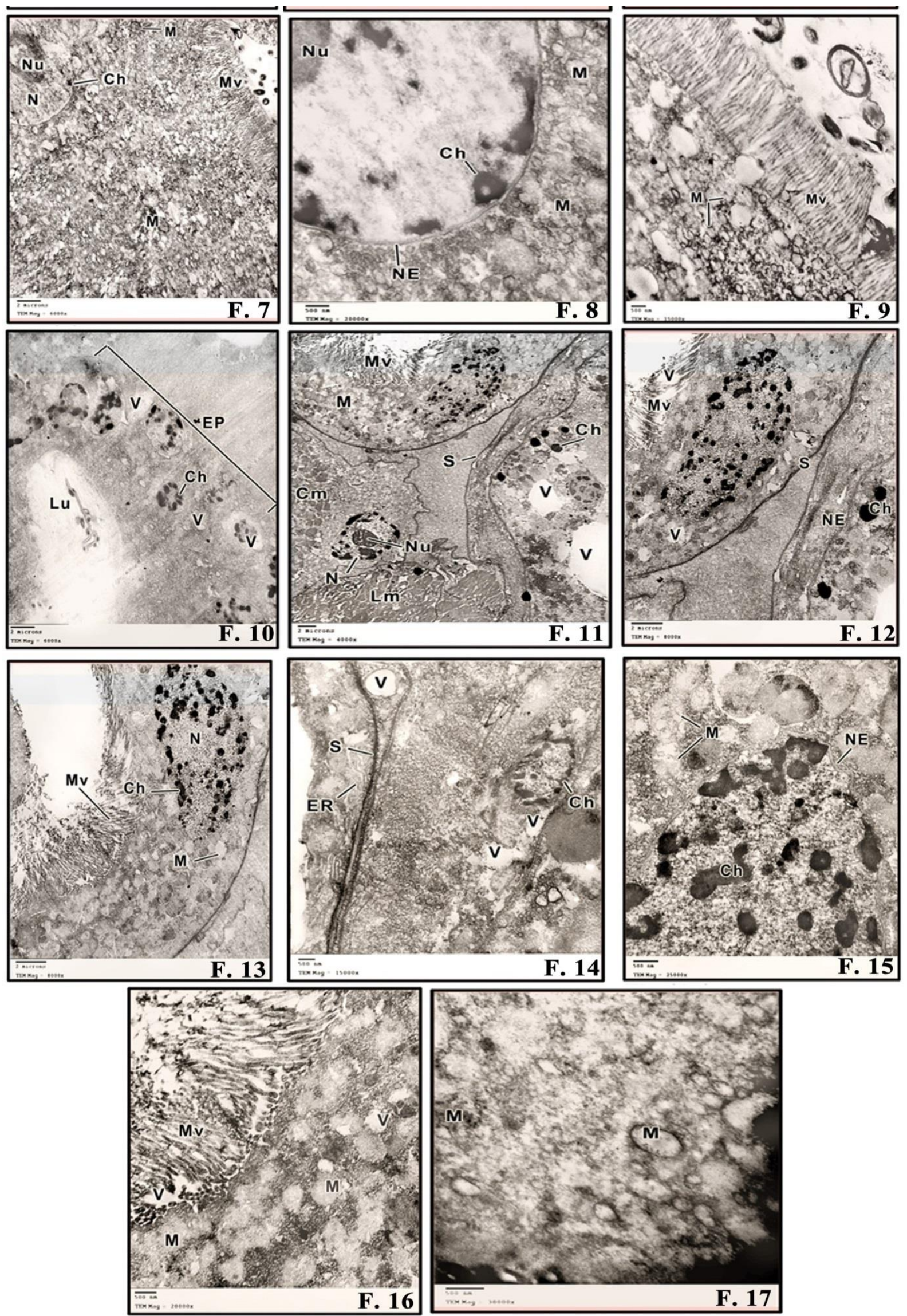